UDC 613.62-037.52+614.8

DOI: 10.21668/health.risk/2019.4.12.eng

\title{
PECULIARITIES OF MORBIDITY AND ASSESSMENT OF OCCUPATIONAL HEALTH RISKS FOR WORKERS WHO CONTACT AEROSOLS OF MAN-MADE MINERAL FIBERS
}

\author{
E.A. Hutsich, G.E. Kosiachenko, S.I. Sychik
}

Scientific Practical Centre of Hygiene, 8 Akademicheskaya Str., Minsk, 220012, Belarus

\begin{abstract}
Our research focused on health of workers who had contacts with aerosols of man-made mineral fibers.
Our research goal was to determine peculiarities related to dynamics and structure of morbidity with temporary disability and to assess occupational health risks for workers who had contacts with aerosols of man-made mineral fibers.

The paper dwells on the results obtained via in-depth interpretation analysis of morbidity with temporary disability among workers who were permanently involved in manufacturing heat insulating boards from mineral wool (the test group); morbidity was analyzed over a 5-year period taking into account workers' sex, age, and working experience. Occupational conditionality of morbidity was assessed via comparative analysis as the test group was compared with the conditional reference group (workers employed at a workshop where cell concrete blocks were manufactured), overall morbidity parameters taken for the whole country, and morbidity parameters taken for construction materials manufacturing. Risk was assessed via applying occupational risk index, calculated on the basis of relative risk and total coefficient of working conditions.

We detected that morbidity with temporary disability among workers from the test group was authentically higher than morbidity among workers from the conditional reference group, regarding both all disease categories, and respiratory organs diseases in particular. Relative risk and etiological fraction of morbidity caused by working conditions indicates that such conditions have direct influence on morbidity with respiratory organs diseases among workers from the test group. Occupational risk index characterizes occupational risk for workers from the test group as being moderate but still requiring specific activities aimed at reducing it, although there is no urgent necessity to perform them. Workers from the test group also tended to have lower "health index" than those form the conditional reference group.

Morbidity with temporary disability among workers from the test group was authentically lower than in the Republic of Belarus on average as well as than standard parameters fixed for construction materials manufacturing; but it was statistically significantly higher than both in the country on average and in the branch for respiratory organs diseases, musculoskeletal and connective tissue diseases; it was also statistically significantly higher than on average in the country for digestive organs diseases and diseases of skin and subcutaneous tissue.
\end{abstract}

Key words: mineral wool manufacturing, man-made mineral fibers, industrial aerosols, working conditions, morbidity, occupational risk, occupational diseases, morbidity dynamics.

The World Health Organization estimates $2.1 \%$ of all the death cases all over the world to be caused by occupational risks; a share of global disease burden associated with exposure to occupational factors reaches $2.7 \%$ [1]. Industrial aerosols traditionally take the $1^{\text {st }}$ rank place among adverse industrial factors for workers from various occupational groups.
There has been a drastic increase in application of various synthetic fibers over the recent years especially after asbestos was completely banned in many countries or its application was significantly limited [2]. These data are confirmed by official statistics in Belarus; according to it, volumes of mineral cotton production increased by $266.5 \%$ from 2005 to $2017^{1,2}$.

(C) Hutsich E.A., Kosiachenko G.E., Sychik S.I., 2019

Ekatsiaryna A. Hutsich - Head of Scientific Organization Department, Junior Researcher at Occupational Hygiene Laboratory (e-mail: ekhutsich@gmail.com; tel.: +375 17 399-44-36; +375 29 694-06-18; ORCID: https://orcid.org/0000-0002-1910-6556).

Grigorij E. Kosiachenko - Doctor of Medical Sciences, Associate Professor, Chief Researcher at Occupational Hygiene Laboratory (e-mail: gekvod@mail.ru; tel.: +375 17 292-80-56; ORCID: https://orcid.org/0000-0001-7343-8028).

Sergej I. Sychik - Candidate of Medical Sciences, Associate Professor, Director (e-mail: rspch@rspch.by; tel.: +375 17 284-13-70; ORCID: https://orcid.org/0000-0002-5493-9799).

\footnotetext{
${ }^{1}$ Industries in the Republic of Belarus: statistic report. Belarus National Statistics Committee. Minsk, 2013, $159 \mathrm{p}$.
}

${ }^{2}$ Industries in the Republic of Belarus: statistic report. Belarus National Statistics Committee. Minsk, 2018, 118 p. 
Production processes applied in manufacturing products out of synthetic mineral fibers involve formation of fine-disperse dust with its particles diameter being less than $10 \mu \mathrm{m}$. This dust deposits in calm air due to gravity force at a speed being less than $1 \mathrm{~cm} / \mathrm{sec}$; consequently, mineral cotton particles persist in working area air and penetrate workers' bronchopulmonary system and gastrointestinal tract [3]. Impacts exerted on a body by such aerosols depend not only on fibers size but also a degree of their biological persistence [4]. And even though several research works indicate that mineral cotton fibers have low biological persistence [5], we should note that production processes for manufacturing ready products based on these fibers involve applying binding components with different structure (phenol-formaldehyde resins are often used). It can substantially change their solubility thus increasing their biological persistence $[2,6]$.

There was a monograph issued by the International Agency for Research on Cancer (IARC) that focused on assessing carcinogenic risks caused by synthetic mineral fibers; according to its authors, glass cotton, mineral cotton, and slag cotton were moved from the group 2B ("probably carcinogenic for people" into the group 3 ("not classified as having carcinogenic effects on a human body"). It was substantiated by research results that indicated there was no increase in frequency of tumors in the lungs and mesothelioma under inhalation exposure to them and their intratracheal penetration into a body [7]. However, there are several works mentioning a correlation between exposure to synthetic mineral fibers and pleura mesothelioma and lung cancer [8-14], as well as cytotoxic and genotoxic effects produced by mineral cotton $[15,16]$. Exposure to synthetic mineral fibers is also considered to be correlated to high risks of pneumoconiosis [17], cardiovascular pathology [3], and hyperkeratosis with highly probable malignant change [18].

Official statistical data collected in Belarus give evidence that occupational morbidity annually decreases; in 2017 there were 84 occupational diseases cases registered in the republic (there were 97 such cases in 2016), and it is not consistent with working conditions existing in the country as $65.4 \%$ work places are estimated as having harmful working conditions [19]. Given that, it becomes truly vital to examine morbidity with temporary disability (morbidity with TD) and to determine an extent to which diseases are caused by occupational factors and occupational health risks existing at work places.

Our research goal was to determine peculiarities related to dynamics and structure of morbidity with TD and to assess occupational health risks for workers who had contacts with synthetic mineral fibers aerosols.

Data and methods. We accomplished our research at the largest industrial enterprise dealing with construction materials production in Belarus, "Gomel'stroimaterialy" public company located in Gomel; among other products, it manufactured heat insulating boards made of mineral cotton.

To examine morbidity with TD among workers who contacted synthetic mineral fibers aerosols, we created our basic test groups that included workers employed at a workshop where heat-insulating materials were produced (Workshop No. 1) in a quantity equal to 1,096 year-round person-years. Our reference group (conventional control) was made up of workers employed at a workshop where cell-concrete blocks were produced (Workshop No. 2) in a quantity equal to 848 year-round person-years.

Groups were created taking into account differences between them as per leading adverse industrial factors existing at work places and similarities as per non-industrial factors (the same locations, communal conditions, and medical support). To create the reference group, we chose a workshop with working conditions which were comparable as per their hazard category at most work places $\left(1^{\text {st }}\right.$ and $2^{\text {nd }}$ hazard categories). What mattered a lot here was a fact that both groups being exposed to industrial aerosols with fibrogenic effects; however, that factor was predominantly caused by synthetic mineral fibers aerosols while workers from the reference group were primarily exposed to fibrous silicon-containing aerosols occurring in working area air.

We statistically analyzed both samplings and revealed that they were comparable as per 
sex as men accounted for $85.3 \%$ in the test group $(n=278)$ and for $81.5 \%$ in the reference group ( $n=221, p=0.275$, Fisher's twotailed exact test); age (age distribution median amounted to 38 in the test group $(31 ; 46)$, and to 41 in the reference group $(33 ; 49), p=0.229$, Mann-Whitney); work experience (work experience median amounted to 8 years in the test group $(4 ; 12)$, and to 11 years in the reference group (5; 16), $p=0.498$, Mann-Whitney); and as per workers' occupations.

To obtain data on morbidity with TD, we examined 2,120 sick leaves issued over a period from 2012 to 2016. We didn't include temporary disability (TD) cases caused by home injuries, sick leaves given to take care of a sick family member, as well as TD cases for workers with their working experience not exceeding 1 year at the moment a disease occurred.

We analyzed morbidity with TD and assessed statistical significance of discrepancies between examined TD parameters according to MG No. 112-9911-99 "In-depth analysis of morbidity with temporary disability"3.

Relative risk (RR), $95 \%$ confidence interval of RR, and etiological fraction (EF) were calculated according to the Application Instruction No. 062-1109 "Assessment criteria and occupational morbidity parameters for complex analysis of impacts exerted by working conditions on workers' health and occupational risks assessment" ${ }^{\text {" }}$.

To assess long-term morbidity dynamics, we calculated growth rates as per geometric mean.

Obtained data were statistically treated and analyzed with STATISTICA 10 applied software. Initial data were given as absolute and relative values with confidence intervals [CI 0.95$]$. Central trends and spreads of quantitative parameters that had approximately normal distribution were given with mean value (M) and error of the mean (m) as $\mathrm{M} \pm \mathrm{m}$. Cen- tral trends and dispersions of quantitative signs with their distribution not being normal were given with median and inter-quartile spread (the $25^{\text {th }}$ and $75^{\text {th }}$ percentiles) as Me $(25 ; 75)$.

We applied Kolmogorov-Smirnov test, Lilleiefors test, and Shapiro-Wilk test as criteria showing that signs were normally distributed in the examined groups. Confidence intervals for frequencies and fractions were calculated as per Wald procedure. We applied Mann-Whitney criterion to compare two independent groups as per quantitative signs with their distribution not being normal. Significance of discrepancies between two independent groups was estimated with Chi-square and Fisher's exact two-tailed test). Critical significance (p) applied to test statistical hypotheses was taken as 0.05 .

Results and discussion. Having analyzed morbidity with TD among workers from the test group taken in dynamics over the examined 5-year period, we detected there was a descending trend in number of TD cases by $22.3 \%$ from 102.3 (95\% CI 88.78-115.89) cases per 100 workers to $72.4(95 \% \mathrm{CI}$ 60.87-83.89) cases; on average, a number of cases decreased by $8.3 \%$ a year (Table 1 ). A number of TD days also tended to go down by $10.0 \%$ from 843.5 (95\% CI 617.44-1,069.48) days per 100 workers to $639.5(95 \% \mathrm{CI}$ 466.53-812.52); however in2013 there was a $3.2 \%$ growth in number of TD cases against 2012, and average duration of a TD case was the longest in 2013 over the examined period and amounted to 10.0 (95\% CI 8.57-11.44) days. Overall, a number of ND cases registered in 2012-2016 was considered to be "above average" in 2012 according to E.L. Notkin's scale for assessing morbidity with temporary disability; 2013-2014, "average"; 2015-2016, "below average"; and a number of TD days was estimated as "average" (20122014) and "below average" (2015-2016).

\footnotetext{
${ }^{3}$ In-depth analysis of morbidity with temporary disability of workers: methodical guidelines. Approved by the Belarus Public Healthcare Ministry on November 30, 1999, No. 112-9911. A collection of official documents on occupational medicine and industrial sanitary. Minsk: The Republican center for Hygiene and Epidemiology, Scientific research Institute for Sanitary and Hygiene, 2001, vol. 8, pp. 79-100.

4 "Assessment criteria and occupational morbidity parameters for complex analysis of impacts exerted by working conditions on workers' health and occupational risks assessment": application instruction. Approved by the Belarus Public Healthcare Ministry on November 24, 2009, Reg. No. 062-1109; developed by R.D. Klebanov [et al]. Minsk, 2009, 33 p.
} 
Morbidity with temporary disability among workers employed by "Gomel'stroimaterialy" public company taken in dynamics over 2012-2016

\begin{tabular}{|c|c|c|c|c|c|c|c|c|}
\hline \multirow[b]{2}{*}{ Year } & \multicolumn{4}{|c|}{$\begin{array}{l}\text { Workshop No. } 1 \\
\qquad M \pm m\end{array}$} & \multicolumn{4}{|c|}{$\begin{array}{c}\text { Workshop No. } 2 \\
\qquad M \pm m\end{array}$} \\
\hline & Cases & Day & $\begin{array}{c}\text { Average } \\
\text { duration } \\
\text { of a TD } \\
\text { case }\end{array}$ & IP & Cases & Day & $\begin{array}{c}\text { Average } \\
\text { duration } \\
\text { of a TD } \\
\text { case }\end{array}$ & IP \\
\hline 2012 & $102.3 \pm 6.92$ & $843.5 \pm 11.32$ & $8.2 \pm 0.4$ & $293.8 \pm 16.31$ & $90.2 \pm 7.42$ & $742.1 \pm 115.89$ & $8.2 \pm 0.53$ & $258.8 \pm 15.83$ \\
\hline 2013 & $91.1 \pm 6.36$ & $870.2 \pm 116.03$ & $9.6 \pm 0.51$ & $281.6 \pm 15.07$ & $92.4 \pm 7.07$ & $785.4 \pm 115.49$ & $8.5 \pm 0.6$ & $269.4 \pm 15.71$ \\
\hline 2014 & $85.9 \pm 6.25^{*}$ & $859.6 \pm 115.9$ & $10.0 \pm 0.73$ & $271.7 \pm 14.56^{*}$ & $66.9 \pm 6.13$ & $619.7 \pm 92.89$ & $9.3 \pm 0.64$ & $203.5 \pm 10.88$ \\
\hline 2015 & $70.5 \pm 5.57 *$ & $693.4 \pm 92.04 *$ & $9.8 \pm 0.74 *$ & $221.1 \pm 10.86^{*}$ & $54.4 \pm 5.68$ & $442.0 \pm 68.00$ & $8.1 \pm 0.43$ & $155.1 \pm 7.11$ \\
\hline 2016 & $72.4 \pm 5.87$ & $639.5 \pm 88.26$ & $8.8 \pm 0.55$ & $215.2 \pm 10.86^{*}$ & $60.5 \pm 6.31$ & $534.9 \pm 86.77$ & $8.8 \pm 0.71$ & $179.9 \pm 9.73$ \\
\hline 2012-201 & $84.4 \pm 2.77^{*}$ & $782.0 \pm 47.24^{*}$ & $9.3 \pm 0.26$ & $256.9 \pm 6.06^{*}$ & $73.4 \pm 2.94$ & $628.9 \pm 43.19$ & $8.6 \pm 0.27$ & $214.8 \pm 5.39$ \\
\hline
\end{tabular}

We compared TD parameters detected in the test group with average long-term parameters taken for the whole country and revealed authentically lower morbidity with TD among workers from the Workshop No. 1 against morbidity with TD in the country in general as per TD days $(t=2.28, p<0.05)$ and as per an integral parameter (IP) that took into account both cases and days $(t=2.47, p<0.05)$. We obtained the same results after comparing morbidity with TD in the test group with standards accepted in construction materials production both as per TD days $(t=3.1, p<0.05)$ and IP $(t=4.18, p<0.05)$.

Lower morbidity with TD among workers employed at the workshop where heatinsulating materials are produced both against country levels and branch ones is probably due to qualitative occupational selection that allows hiring workers with initially greater adaptation abilities. It is well-known that workers who are employed ad harmful productions are in general healthier than their counterparts who work in rather comfortable conditions and a share of people with functional limitations and weak health is usually lower among them [20]. We should also remember that labor turnover grows proportionate to working conditions becoming more harmful as workers with weaker health leave; working conditions existing in the workshop where heat-insulating materials were manufactured were assessed as having 1-4 harmful categories for $87 \%$ of total work places.

Dynamics of morbidity with TD detected in the reference group revealed a trend quite similar to that in the test group. Thus, a number of TD cases detected in the Workshop No. 2 decreased by $25.6 \%$ over the examined 5-year period, from 90.2 (95\% CI 75.78-104.78) cases per 100 workers to $60.5(95 \% \mathrm{CI}$ 48.16-72.89); a fall in number of cases was more intensive than in the test group and on average amounted to $9.5 \%$ a year. Duration of TD (number of days) also decreased by $21.5 \%$ in 2012-2016, from 742.1 (95 \% CI 514.92-969.22) days per 100 workers to $534.9(95 \%$ CI 364.80-704.93). In general, in 2012-2016 number of TD cases in the Workshop No. 2 were estimated as "average" as per E.L. Notkin's scale (2012-2013); "below average" (2014, 2016): and "low" (2015); duration of TD (days) was estimated as "below average" (2012-2014); "low" (2016); and "extremely low" (2015).

Morbidity with TD was statistically significantly higher in the test group than in the reference one. Comparative analysis of morbidity with TD as per TD cases revealed authentically higher levels in the test group against the reference one; by $28.4 \%$ in 2014 
$(t=2.18, p<0.05)$ and by $29.6 \%$ in 2015 $(t=2.02, p<0.05)$. Average long-term number of TD cases over the whole 5-year period was also higher by $15.0 \%(t=2.73, p<0.05)$. Number of TD cases per 100 workers was by $56.9 \%$ authentically higher in the Workshop No. 1 than in the Workshop No. 2 in 2015 $(t=2.20, p<0.05)$ and on average by $24.3 \%$ over the whole examined period $(t=2.39$, $p<0.05)$.

IP also was higher for morbidity with TD in the test group from 2014 to 2016 varying from $19.6 \%(t=2.42, p<0.05)$ to $42.6 \%$ $(t=5.08, p<0.05)$, and on average by $19.6 \%$ over 2012-2016 $(t=5.20, p<0.05)$. We also calculated RR and EF as per days of TD (RR 1.24 [1.12; 1.38], EF 19.6\%) and as per a number of sick people (RR 1.17 [1.09; 1.26], EF $14.8 \%$ ) and revealed that morbidity with TD was statistically authentically higher in the test group than in the reference one. Occupational risk index calculated on the basis of relative risk and a total quotient describing working conditions (3.9) was equal to 3 and it indicated that occupational risk was moderate for workers from the test group; consequently, specific activities were required to reduce it but there was no necessity to implement them immediately.

Shares of workers who fell sick over the 5-year period from 2012 to 2016 were similar in both groups and tended to decrease just as other parameters of morbidity with TD. In general, a number of sick workers in the Workshop No. 1 in 2012-2016 was estimated as "average" and "below average' as per E.L. Notkin's scale; in the Workshop No. 2, "below average" and "low". We compared average long-term "shares of workers who fell sick" (49.3\% in the Workshop No. 1 and $41.4 \%$ in the Workshop No. 2) and "health index" (50.7\% in the Workshop No. 1 and $58.6 \%$ in the Workshop No. 2) and it allowed us to detect a higher share of workers who fell sick in the test group and, consequently, lower "health index" $\left(\chi^{2}=11.95, p=0.0005\right.$, Chi-square).

When examining morbidity with TD, we also aimed to assess gravity of diseases; to do that, we applied such a parameter as a number of workers who frequently fell sick and remained on a sick leaf for a long period of time as well as a share of workers who were taken to in-hospital departments. Our analysis of number of workers who often fell sick and remained on a sick leaf for a long period of time revealed that there were no statistically significant discrepancies in overall number of workers who could be ranked as "frequently sick" and "frequently sick for a long time" in the test and reference groups. A share of workers who could be ranked as "sick for a long time" on average amounted to $3.1 \%$ in the Workshop No. 1 over the examined period and it was authentically higher than in the reference group where it was equal to $1.5 \%\left(\chi^{2}=4.99, p=0.026\right.$, Chi-square). A share of workers who were taken to in-hospital departments amounted to $13.3 \%$ in the Workshop No. 1 over the whole examined period and there were no statistically significant discrepancies between both groups as per this parameter as it was equal to $11.9 \%$ among workers form the Workshop No. 2.

We also examined morbidity structure as per specific nosologies using average longterm number of TD cases and duration of TD cases in days in the Workshop No. 1; the results are shown in Figure 1. Respiratory organs diseases took the $1^{\text {st }}$ rank place in morbidity with TD, both as per a number of cases and days of TD, with their specific weight being equal to $52.5 \%$ and $40.8 \%$ accordingly. Acute respiratory infections accounted for the highest specific weight among such nosologies, $95.9 \%$ as per TD cases and $93.1 \%$ as per TD days.

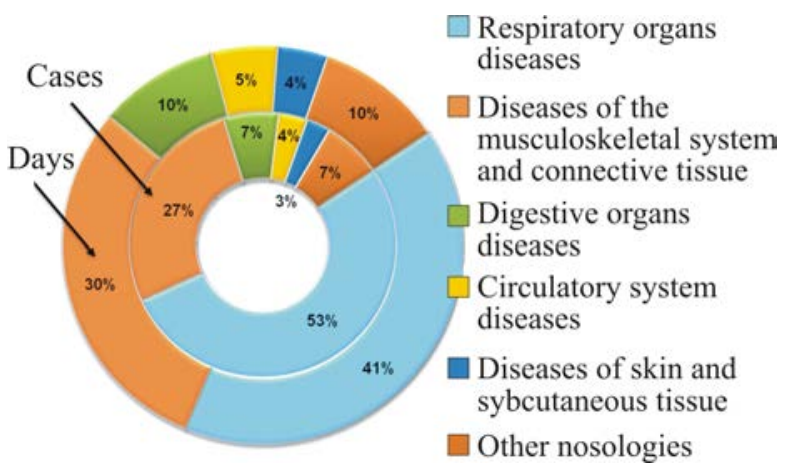

Figure 1. Structure of Td cases and TD days In the test group over 2012-2016 (\%) 
The $2^{\text {nd }}$ rank place belonged to diseases of the musculoskeletal system and connective tissue, their specific weight being equal to $27.1 \%$ as per cases and $29.8 \%$ as per TD days. Digestive organs diseases took the $3^{\text {rd }}$ place both as per cases $(6.7 \%)$ and days $(9.7 \%)$.

We performed comparative assessment of morbidity with TD as per specific nosologies and it allowed us to reveal that morbidity with respiratory organs diseases was authentically higher among workers form the Workshop No. 1 than among their counterparts from the Workshop No. 2, as per TD cases $(t=3.04$, $p<0.05)$, TD days $(t=3.21, p<0.05)$ and IP $(t=14.64, p<0.05)$. Calculation of $\mathrm{RR}$ and EF as per a number of workers who fell sick (RR 1.20 [1.04; 1.38], EF 16.5\%) also allowed detecting impacts exerted by working conditions existing in the Workshop No. 1 (the test group) on occurrence of respiratory organs diseases.

It is important to note that in spite of generally lower morbidity with TD in the Workshop No. 1 against country and branch levels, morbidity with respiratory organs diseases was authentically higher among workers from the Workshop No. 1 than in the country in general (as per cases, $t=2.51, p<0.05$; days, $t=2.10$, $p<0.05$; IP, $t=11.89, p<0.05)$ and in the branch (as per cases, $t=3.66, p<0.05$; as per days, $t=4.55, p<0.05$; as per IP, $t=15.59$, $p<0.05)$. Peculiarities in occurrence of respiratory organs diseases detected in the test group indicate that this pathology is an occupational one.

Morbidity with diseases in the musculoskeletal system and collective tissue were also statistically authentically higher among workers from the test group than in the country in general (as per cases, $t=6.84, p<0.05$; TD days, $t=6.13, p<0.05$; IP, $t=19.89$, $p<0.05)$ and standards fixed for the branch (as per cases, $t=8.66, p<0.05$; TD days, $t=3.41, p<0.05$; IP, $t=28.69 ; p<0.05)$. Workers from the test group also suffered from digestive organs diseases (as per cases, $t=2.22, p<0.05$; TD days, $t=6.51, p<0.05$; IP, $t=5.63, p<0.05)$ and skin and subcutaneous tissue diseases (as per days, $t=6.74$, $p<0.05$; IP, $t=3.58, p<0.05)$ authentically more frequently than the country population in general.

We analyzed data on morbidity with TD in both groups depending on gender differences and it allowed us to reveal the following peculiarities. Number of TD days and IP calculated for year-round female workers form the Workshop No. 1 were authentically lower than the same parameters calculated for male workers (as per days, $t=2.77, p<0.05$; IP, $t=2.84, p<0.05)$. We compared the parameters in the test and reference groups and revealed that morbidity among men form the Workshop No. 1 was higher than among their counterparts from the Workshop No. 2 (as per cases, $t=3.89$, $p<0.05$; days, $t=2.60, p<0.05$; IP, $t=6.32$, $p<0.05)$. On the contrary, morbidity among female workers from the test group was lower as per TD cases than among their counterparts from the reference group $(t=2.05, p<0.05)$. The detected peculiarities may also indicate that registered diseases are occupational.

We examined age-related labor losses in the test and reference group and revealed that as workers' age grew, TD parameters went down in both groups. The highest morbidity in the Workshop No. 1 was registered among workers younger than 30 and was equal to 131.5 (95\% CI 115.75-147.30) TD cases per 100 workers and 958.1 (95\% CI 694.52-1,221.74) TD days per 100 workers. The lowest morbidity with TD was registered among workers aged "50 and older" and was equal to 63.5 (95\% CI 51.78-75.19) TD cases per 100 workers and 769.7 (95\% CI 543.52-995.80) TD days per 100 workers. These peculiarities revealed via analysis that took workers' age into account can be explained by activation of adaptation mechanisms in young workers who had to work in adverse working conditions.

We examined morbidity among workers as per different age groups and revealed that morbidity in the test group was authentically higher than in the reference group among workers younger than 30 (as per cases, $t=2.86, p<0.05$; IP, $t=2.98, p<0.05)$; workers aged 40-49 (as per cases, $t=2.07, p<0.05$; TD days, $t=2.12, p<0.05$; IP, $t=4.43$, $p<0.05$ ); workers aged 50 and older (as per 
TD days, $t=2.33, p<0.05 ;$ IP, $t=4.89$, $p<0.05)$. However, morbidity with TD among workers from the Workshop No. 2 aged 30-39 was higher than in the same age group in the Workshop No. 2 (as per cases, $t=2.12$, $p<0.05$; IP, $t=2.59, p<0.05)$.

We analyzed labor losses depending on work experience and revealed that the highest morbidity in the test was detected among workers with their work experience being shorter than 5 years; it was equal to 112.6 (95\% CI 100.12-125.06) TD cases per 100 workers and 951.8 (95\% CI 728.03-1,175.57) TD days per 100 workers. As working experience became longer, morbidity with TD went down and it was minimal among workers with their work experience being 15 years and longer; it was equal to $50.5(95 \% \mathrm{CI}$ 40.95-59.99) TD cases per 100 workers and 685.5 (95\% CI 502.50-870.39) TD days per 100 workers. These trends in labor losses depending on work experience are probably due to a period during which a worker's body adapted to apparent impacts exerted by adverse occupational factors and labor processes and development of compensatory mechanisms as their contacts with those adverse factors grew longer.

Comparative analysis of morbidity with TD in both groups depending on work experience revealed that it was authentically higher among workers from the test group than from the reference group for workers with their work experience being equal to $1-4$ years (as per cases, $t=2.23, p<0.05$; IP, $t=2.78$, $p<0.05$ ) and 5-9 years (as per IP, $t=2.59$, $p<0.05)$.

We calculated occupational health losses for workers from the Workshop No. 1 and No. 2 basing on average annual morbidity with TD and data on age and work experience of workers from the test and the reference group using a constant regression coefficient that characterized morbidity among workers who performed their tasks in optimal working conditions. We analyzed the obtained results and revealed that occupational health losses amounted to $32.3 \%$ in the test group over the examined period (substantial losses, the $3^{\text {rd }}$ category) and it was higher than in the reference group where they amounted to $14.9 \%$ (acceptable losses, the $2^{\text {nd }}$ category $)\left(\chi^{2}=523.9\right.$, $p<0.00001$, Chi-square).

Conclusions. Therefore, we analyzed dynamic processes and structure of morbidity with TD among workers employed at the workshop where heat-insulating materials were produced and compared the results with the reference (conventional control) group that included workers employed at the workshop where cellconcrete blocks were produced. We also compared the results with average country levels and standards fixed for the construction materials production branch; we assessed occupational risks and occupational morbidity. All that allowed us to make the following conclusions.

1. Analysis of morbidity with TD in the test group taken in dynamics over the examined 5-year period revealed an descending trend in number of TD cases that went down by $22.3 \%$ and number of TD days that decreased by $10.0 \%$.

2. Morbidity with TD among workers from the test group was authentically higher than in the reference group over the whole 5 -year period, by $15.0 \%$ as per TD cases; as per TD days, by $24.3 \%$; as per IP, by $19.6 \%$. Morbidity with respiratory organs diseases was higher among workers from the Workshop No. 1 than among those from the Workshop No. 2 as per TD cases, TD days, and IP. Calculation of relative risk and etiological fraction as per a number of sick workers (RR 1.20 [1.04; 1.38$]$, EF $16.5 \%$ ) also allowed establishing that working conditions exerted their influence on occurrence of respiratory organs diseases among workers from the test group.

3. Analysis of average long-term morbidity with TD allowed revealing statistically significantly higher number of workers who fell sick and accordingly lower "health index" in the test group against the reference one $\left(\chi^{2}=11.95, p=0.0005\right.$, Chi-square) .

4. Morbidity with TD among workers from the test group was authentically lower as per TD days and IP than average annual morbidity taken for the country as a whole and standards fixed for construction materials pro- 
duction. However, morbidity taken as per specific nosologies was statistically significantly higher in the test group than in the country and the branch as regards respiratory organs diseases, diseases of the musculoskeletal system and connective tissue; it was also higher than in the country as a whole as per digestive organs diseases and skin and subcutaneous tissue diseases.

5. $\mathrm{RR}$ and $\mathrm{EF}$ as per $\mathrm{TD}$ days (RR 1.24 [1.12; 1.38], EF $19.6 \%$ ) and as per a number of sick workers (RR 1.17 [1.09; 1.26], EF $14.8 \%$ ) indicate that morbidity with TD was statistically authentically higher in the test group than in the reference group. Occupational risk index indicates that occupational risk in the test group is moderate and specific measures are required to reduce it but it is not necessary to implement them immediately. Average long-term occupational health losses amounted to $32.3 \%$ in the test group (substantial losses, the $3^{\text {rd }}$ category) and it was higher than in the reference group where they amounted to $14.9 \%$ (acceptable losses, the $2^{\text {nd }}$ category) $\left(\chi^{2}=523.9, p<0.00001\right.$, Chi-square).

6. Overall number of workers who were ranked as "frequently sick" and "frequently sick for a long time" didn't have any discrepancies in the test group against the reference one; but an average long-term share of year- round workers from the Workshop No. 1 who were considered "sick for a long time" was authentically higher than in the reference group $\left(\chi^{2}=4.99, \quad p=0.026\right.$, Chi-square $)$. A share of workers form the Workshop No. 1 taken to in-hospital departments didn't have any statistically significant discrepancies from a number of TD cases that involved a worker from the reference group being taken to an inhospital department.

7. Morbidity with TD in the test group had gender-related differences. Detected peculiarities could also indicate that registered diseases were occupational.

8. Morbidity with TD in the test group depended on a worker's age and work experience. As age and work experience grew, morbidity with TD tended to decrease; it is due to activation of adaptation mechanisms in young workers who had to work in adverse working conditions and development of compensatory mechanisms as their contacts with adverse factors grew longer.

Funding. The research was accomplished within "Health and Environment" branch scientific and technical program funded by the Belarus Public Healthcare and the Republican Scientific and Practical Center for Hygiene.

Conflict of interests. The authors declare there is no any conflict of interests.

\section{References}

1. Wolf J., Prüss-Ustün A., Ivanov I., Mudgal S., Corvalán C., Bos R., Neira M. Preventing disease through a healthier and safer workplace. Geneva, World Health OrganizationPubl., 2018, 96 p.

2. Ross C.S., Lockey J.E. Vrednoe vozdeistvie na zdorov'e iskusstvennykh volokon [Adverse effects produced on health by synthetic fibers]. Available at: http://base.safework.ru/iloenc?print\&nd= $857400205 \&$ spack $=110$ LogLength $=0$ (06.08.2019) (in Russian).

3. Kopytenkova O.I., Levanchuk A.V., Tursunov Z.Sh. Assessment of health damage due to exposure to mineral wool fine dusts. Kazanskii meditsinskii zhurnal, 2014, vol. 95, no. 4, pp. 570-574 (in Russian).

4. Harrison P., Holmes P., Bevan R., Kamps K., Levy L., Greim H. Regulatory risk assessment approaches for synthetic mineral fibres. Regulatory Toxicology and Pharmacology, 2015, vol. 73, no. 1, pp. 425-441. DOI: 10.1016/j.yrtph.2015.07.029

5. Kudo Y., Aizawa Y. Safety Evaluation of Rock Wool after Nasal Inhalation in Rats. Industrial Health, 2011, vol. 49, no. 1, pp. 47-55. DOI: 10.2486/indhealth.ms 1146

6. Wohlleben W., Waindok H., Daumann B., Werle K., Drum M., Egenolf H. Composition, Respirable Fraction and Dissolution Rate of 24 Stone Wool MMVF with their Binder. Particle and Fibre Toxicology, 2017, vol. 14, no. 1, 29 p. DOI: 10.1186/s12989-017-0210-8 
7. Man-made Vitreous Fibres. World Health Organization. International agency for research on cancer. Lyon, IARC Press Publ., 2002, 430 p.

8. Pohlabeln H., Jöckel K.H., Brüske-Hohlfeld I., Möhner M., Ahrens W., Bolm-Audorff U., Arhelger R., Römer W. [et al.]. Lung cancer and exposure to man-made vitreous fibers: results from a pooled case-control study in Germany. American Journal of Industrial Medicine, 2000, vol. 37, no. 5, pp. 469-477. DOI: 10.1002/(sici)1097-0274(200005)37:5<469::aid-ajim3>3.0.co;2-d

9. Wardenbach P., Rödelsperger K., Roller M., Muhle H. Classification of man-made vitreous fibers: Comments on the revaluation by an IARC working group. Regulatory toxicology and pharmacology, 2005, vol. 43, no. 2, pp. 181-193. DOI: 10.1016/j.yrtph.2005.06.011

10. Rödelsperger K., Jöckel K.H., Pohlabeln H., Römer W., Woitowitz H.J. Asbestos and manmade vitreous fibers as risk factors for diffuse malignant mesothelioma: results from a German hospitalbased case-control study. American journal of industrial medicine, 2001, vol. 39, no. 3, pp. 262-275. DOI: 10.1002/1097-0274(200103)39:3<262::aid-ajim1014>3.0.co;2-r

11. Kashansky S.V. Mesothelioma in Russia: systematic review of 3576 published cases from occupational medicine viewpoint. Meditsina truda i promyshlennaya ekologiya, 2008, no. 3, pp. 15-21 (in Russian).

12. Muzalevsky P.N., Shoikhet Ya.N, Lazarev A.F., Grigoruk O.G. Mesotelioma: prevalence and modified factors (Literature review). Sibirskii onkologicheskii zhurnal, 2007, no. 2, pp. 77-83 (in Russian).

13. Varyvonchyk D.V. Epidemiology of malignant mesothelioma in Ukraine (2001-2011). Ukrä̈n'kii zhurnal z problem meditsini pratsi, 2012, vol. 33, no. 4, pp. 56-69.

14. Kundiev Yu.I., Varivonchik D.V. Professional'nyi rak: zlokachestvennaya mezotelioma [Occupational cancer: malignant mesothelioma]. Kiev, VD Avitsena Publ., 2015, 192 p. (in Russian).

15. Cavallo D., Campopiano A., Cardinali G., Casciardi S., De Simone P., Kovacs D., Perniconi B., Spagnoli G. [et al.]. Cytotoxic and oxidative effects induced by man-made vitreous fibers (MMVFs) in a human mesothelial cell line. Toxicology, 2004, vol. 201, no. 1-3, pp. 219-229. DOI: 10.1080/02786820500380198

16. Staruchova M., Collins A.R., Volkovova K., Mislanová C., Kovacikova Z., Tulinska J., Kocan A., Staruch L. [et al.]. Occupational exposure to mineral fibres. Biomarkers of oxidative damage and antioxidant defence and associations with DNA damage and repair. Mutagenesis, 2008, vol. 23, no. 4, pp. 249-260. DOI: $10.1093 /$ mutage/gen004

17. Fireman E. Man-made mineral fibers and interstitial lung diseases. Current Opinion in Pulmonary Medicine, 2014, vol. 20, no. 2, pp. 194-198. DOI: 10.1097/MCP.0000000000000035

18. Mukhammadiyeva G.F., Bakirov A.B., Karimova L.K., Karimov D.O., Beigul N.A., Gimaeva Z.F. Risk factors and features of occupational diseases in workers engaged into artificial mineral fibers production. Meditsina truda i promyshlennaya ekologiya, 2018, no. 1, pp. 19-23 (in Russian).

19. Mikulich I.V., Rakevich A.V., Kapustinskaya T.A., Biryuk T.I. Sostoyanie uslovii truda i professional'noi zabolevaemosti v Respublike Belarus' za 2017 g. [Working conditions and occupational morbidity in the Republic of Belarus in 2017]. Minsk, Respublikanskii tsentr gigieny, epidemiologii i obshchestvennogo zdorov'ya Publ., 2018, 11 p. (in Russian).

20. Sorokin G.A. The age and work experience dynamics of indices of health of employees as criteria for comparison of occupational and non-occupational risks. Gigiena $i$ sanitariya, 2016, vol. 95, no. 4, pp. 355-360 (in Russian).

Hutsich E.A., Kosiachenko G.E., Sychik S.I. Peculiarities of morbidity and assessment of occupational health risks for workers who contact aerosols of man-made mineral fibers. Health Risk Analysis, 2019, no. 4, pp. 113-121. DOI: 10.21668/health.risk/2019.4.12.eng

Received: 14.08 .2019

Accepted: 03.12.2019

Published: 30.12 .2019 